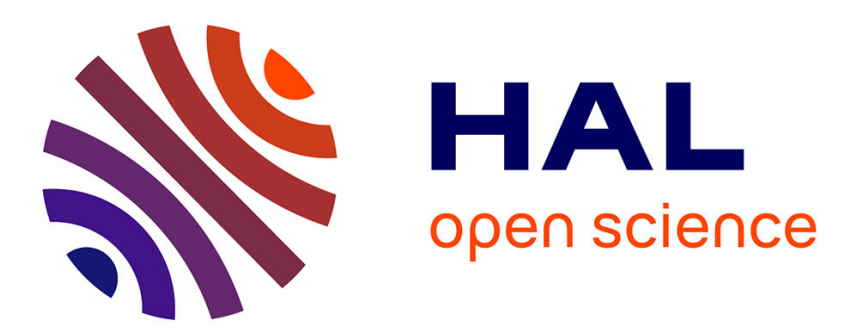

\title{
Chains of influence in Himalayan grammars: models and interrelations shaping descriptions of Tibeto-Burman languages of Nepal
}

\author{
Barbara Kelly, Aimée Lahaussois
}

\section{- To cite this version:}

Barbara Kelly, Aimée Lahaussois. Chains of influence in Himalayan grammars: models and interrelations shaping descriptions of Tibeto-Burman languages of Nepal. Linguistics, 2021, 59 (1), pp.207-245. hal-01899141v2

\author{
HAL Id: hal-01899141 \\ https://hal.science/hal-01899141v2
}

Submitted on 16 Sep 2019

HAL is a multi-disciplinary open access archive for the deposit and dissemination of scientific research documents, whether they are published or not. The documents may come from teaching and research institutions in France or abroad, or from public or private research centers.
L'archive ouverte pluridisciplinaire HAL, est destinée au dépôt et à la diffusion de documents scientifiques de niveau recherche, publiés ou non, émanant des établissements d'enseignement et de recherche français ou étrangers, des laboratoires publics ou privés. 


\title{
Chains of influence in Himalayan grammars: models and interrelations shaping descriptions of Tibeto-Burman languages of Nepal.
}

\begin{abstract}
This paper examines comparability of descriptive grammars across typologically different languages. Focusing on the Nepal Himalayas, which has high language diversity that extends beyond areal, genetic, and historical categorization, the paper examines similarities across grammars and the influences motivating these. It reports on the construction and use of a relational database comprising materials from 18 descriptive grammars of Tibeto-Burman languages of Nepal written over a 30-year period. This includes a small sub-database of metadata, noting grammarian linguistic training, career affiliations, and dissertation supervisors and a larger sub-database of fully tagged tables of contents for each of the grammars. The overarching relational database links sections containing similar content, enabling search functions to explore the locations of similar information and feature labels across grammars in the database. While some grammar-features in the corpus reflect broader structural properties across grammars, findings indicate strong local influences. We find evidence of three foundational linguistic 'schools' connecting the structural organization of the grammars across multiple generations of linguists, correspondences across chapter titles, sections, as well as 'school'-influenced organization of verbal paradigms, treatment of marginal topics, and terminological choices.
\end{abstract}

Key words: grammaticography, language description, language typology, Himalayan grammars

\section{Introduction}

This article lays the groundwork for an investigation into issues of comparability of descriptive grammars across typologically different languages. We focus on one geographic area with high language diversity, the Nepal Himalayas, as we seek to determine, using a database of tables of contents of 18 descriptive grammars (published from 1987 to 2016), what organizational principles and influences thereupon motivate the structuring of grammatical descriptions.

This work comes about through a burgeoning awareness of the influences of our own linguistic training as descriptive linguists and in turn our training of junior linguists. This has led us to consider the historical and areal models that shape the frameworks for our linguistic descriptions. Much has been written recently about terminological choices and their consequences (see for example papers in Linguistic Typology 20:2 (2016)), and we seek to ask

\footnotetext{
*Barbara F. Kelly, ....., Email: b.kelly@unimelb.edu.au

A* Aimée Lahaussois (ORCID 0000-0002-9355-6205), Histoire des théories linguistiques, CNRS, Université de Paris, F-75013 Paris, France; Email: aimee.lahaussois@cnrs.fr
} 
similar questions about the effects of the organization of material presented in descriptive grammars. ${ }^{1}$

The time period covered by our corpus is one of substantial change in typological theory, accompanied by the production of large database tools, such as WALS (Dryer and Haspelmath 2013), and the expansion of Ethnologue (Grimes et al. 1988) and the UNESCO Languages in Danger Atlas (Moseley 2010) as well as Glottolog which version 3.4 lists as having 2564 published descriptive grammars over 300 pages in length with a further 1986 shorter grammatical sketches (Hammarström et al. 2019). Another change over the time period in question is the emergence of a number of field methods and grammar writing manuals: at the time of publication of the first grammar in our corpus, these were rare (Samarin 1967 appears to be the first field linguistics manual to be published and widely available; see Lahaussois 2019), whereas starting from the late 1990's, a great many of these manuals appeared on the market. The manuals are likely to have influenced budding grammarians and shaped their approach to fieldwork and grammar writing. Beyond manuals, other tools have almost certainly also shaped the way in which fieldwork and grammar writing are carried out, such as questionnaires: The ESF-funded EUROTYP project (1990-1994) resulted in the development of a number of questionnaires, many of which are being used in field situations far from the linguistic areas they were originally designed to survey. Websites collecting and archiving questionnaires, such as the popular Leipzig MPI Typological tools for field linguistics ${ }^{2}$, or the more recent TULQuest ${ }^{3}$, have emerged to make these tools available to descriptive linguists.

In addition to developments in theories and tools which have potential to shape how people carry out fieldwork and write grammars, there are also a number of more subliminal influences (see Gawne et al 2017). While modern linguists might refer to Basic Linguistic Theory (Dryer 2006, Dixon 2010, Aikhenvald 2015), models for analyzing and writing about grammar are grounded in historical grammaticographical traditions. Two of these traditions are relevant for the geographical area covered by the grammars in our corpus, namely the Paninian model and the Greco-Latin model. The first of these, based on the 5th c. BC. description of Sanskrit grammar by Panini, has served as a model for the description of a great number of languages, from South Asia, such as Tamil, to the Algonquian languages of North America (Aussant 2017). It is characterized by an emphasis on derivational morphology, with specific terminology for derivational procedures (Lambert-Brétière, in press). The Greco-Latin tradition, characterized by an organization around the parts of speech, was widely used by missionary linguists to describe newly discovered languages, despite the inadequacy of Latin parts of speech for typologically different languages (Colombat et al 2010). In the case of languages of Nepal, even for linguists with strongly guided academic training and affiliations, a missionary affiliation appears to influence what is included in their grammars, which are more likely to have a parts-of-speech organizational scheme (see Lahaussois 2016).

\footnotetext{
${ }^{1}$ One of the most obvious effects of grammar organization is the accessibility of the data for comparative purposes. Traditional grammars' part of speech organization is a model in which readers know where to find the information they are seeking. This is also at the heart of the Comrie-Smith grammar template (Comrie and Smith 1977), with identically-identified sections facilitating comparison. At the other end of the spectrum are Boas-inspired grammars which are organized according to the genius of the language of description, in which not only the order of treatment of topics but the very choice of topics will differ considerably from grammar to grammar.

${ }^{2}$ https://www.eva.mpg.de/lingua/tools-at-lingboard/tools.php

${ }^{3}$ http://tulquest.huma-num.fr
} 
The structure of the paper is as follows: We first describe the corpus of grammars we have used for our study and the two databases built to examine the metadata and data for the descriptions. Next, we explore some of the general features of the corpus, such as details about the macrostructure (front and back matter, range of sizes and number of chapters). We then provide a taxonomy of features that emerge from a study of the tables of contents of the grammars in the corpus, essentially exploring the organizational principles that have been applied to the structure of the grammars. This is followed by a study of some topics of areal relevance (sound-symbolic parts of speech, evidentiality) in order to examine where these topics are covered in the structure of the grammar, and what clues their treatment and analysis give us about influences on the authors of the grammars. Finally, we look more closely at external influences that have shaped the grammars, exploring in particular the mentor > student relationship by studying the grammars in the corpus for which such links can be established. We conclude with a section discussing the significance of this type of metaanalytical work and its contribution to grammaticography as a whole.

\section{Corpus description}

The following sections describe the corpus which is the basis for the study presented here and the database emanating from that corpus.

\subsection{The grammar corpus}

In this study we report on the patterns found in a corpus of 18 grammars ${ }^{4}$ of languages of Nepal published between 1987 and 2016 from different sub-branches of the Tibeto-Burman (henceforth TB) family. These languages were chosen because of the great morphological diversity found across TB languages spoken in Nepal, with features which differ markedly (such as inflectional morphology and evidential marking) and others which are shared. ${ }^{5}$

In Table $1^{6}$, we present some general information about the grammars in the corpus. The main topic of this paper, namely an interrogation of the ways in which the full table of contents reflects deeper analysis within the grammar and the types of choices made by linguists, will be presented in section 3.2.

Table 1. Corpus grammars across authors and size.

\begin{tabular}{lllll}
\hline Author & Language & Branch $^{\mathbf{7}}$ & $\begin{array}{l}\text { \# of pages [incl. } \\
\text { appendices] }\end{array}$ & \# of chapters \\
\hline van Driem (1987) & Limbu & Kiranti & $276[565]$ & $\begin{array}{l}10 \text { (+ } \\
\text { introduction) }\end{array}$ \\
\hline Michailovsky (1988) & Hayu & Kiranti & $204[234]$ & 5 \\
\hline van Driem (1993) & Dumi & Kiranti & $275[452]$ & 9 \\
\hline
\end{tabular}

\footnotetext{
${ }^{4}$ While grammars and sketch grammars may be considered different in some respects (Mosel 2006a) we make no distinction between works that are considered 'grammars' versus 'sketch grammars' since the distinction is not always apparent in the actual work and all grammars appear to be on a continuum, with no clear binary opposition. Note that throughout the term "grammar" refers to the grammatical description by a given linguist at a given time of a language spoken in a defined community.

${ }^{5}$ This diversity is well documented, and as a result the languages of Nepal are used for a number of comparative projects. See, for example, Bickel 2003.

${ }^{6}$ Readers will notice two grammars each by van Driem and Ebert. This is a conscious choice based on the prominence of these two major scholars of Nepal languages and the widespread availability and thus accessibility of these descriptions.

${ }^{7}$ Linguistic groupings are according to Bradley 1997.
} 


\begin{tabular}{lllll}
\hline Ebert (1997a) & Camling & Kiranti & $68[76]$ & 5 \\
\hline Ebert (1997b) & Athpare & Kiranti & $157[283]$ & 6 \\
\hline Rutgers (1998) & Yamphu & Kiranti & $318[632]$ & 11 \\
\hline Watters (2002) & Kham & Central Himalayan & $456[467]$ & 19 \\
\hline Hildebrandt (2004) & Manange & West Bodish & $121[192]$ & 5 \\
\hline Kelly (2004) & Sherpa & Central Bodish & $75[131]$ & 5 \\
\hline Poudel (2006) & Dhankute Tamang & West Bodish & $178[181]$ & 4 \\
\hline Genetti (2007) & Dolakha Newar & Central Himalayan & $515[578]$ & 21 \\
\hline Doornenbal (2009) & Bantawa & Kiranti & $338[497]$ & 8 \\
\hline King (2009) & Dhimal & Subgrouping unclear & $288[612]$ & 5 \\
\hline Hari (2010) & Yohlmo & Central Bodish & $127[127]$ & 7 \\
\hline Regmi (2012) & Bhujel & Central Himalayan & $161[206]$ & 12 \\
\hline Turin (2012) & Thangmi & West Himalayish & 484 (vol 1, & 7 \\
& & & grammar) & \\
\hline Shackow (2015) & Yakkha & Kiranti & $527[603]$ & 17 \\
\hline Gawne (2016) & Lamjung Yolmo & Central Bodish & $160[171]$ & 8 \\
\hline
\end{tabular}

\subsubsection{Size of grammars}

As can be seen in Table 1, grammars in the corpus range in number of pages from 68 (Ebert 1997a) to 527 pages (Schackow 2015), excluding appendices ${ }^{8}$. There are substantial differences across the corpus in terms of what elements authors chose to consider as the main part of their grammar, versus what they consider as front or back matter. In some cases, texts and glossaries are considered to be part of the grammar, and given chapter status (Gawne 2016, Watters 2002); in other cases, texts and glossaries are set apart in appendices (Schackow 2015, Genetti 2014, van Driem 1987, 1993, Ebert 1997b, Kelly 2004, Hildebrandt 2004, Michailovsky 1988, Doornenbal 2009). In yet other descriptions, texts and glossaries are set aside in a different volume (Ebert 1997a, Turin 2012), or in distinctly labeled parts of the grammar ('Part 2', in Rutgers 1998). In one case, the bibliography is considered to be a chapter (Hari 2010). The diversity of approaches results in some challenges in evaluating the relative sizes of the grammars; our method is to assume that anything given a chapter heading is considered to be part of the grammar proper, and the page counts we use thus refer to material presented under chapter headings in the table of contents of the grammars.

The size of a grammar is an important element in determining what material is included in the description, as we shall see when looking in detail at the treatment of certain topics and whether they are described in the grammars in the corpus, and if so, in what location. This will be treated in section 4. At a less detailed level, the general trend appears to be that shorter grammars are organized around parts of speech, moving towards a linguistics subfield organization as they get bigger (phonology-morphology-syntax), with the very largest containing both of these schemes in addition to chapters on various grammatical categories.

While Pawley (2014) suggests that PhD grammars produced at Australian universities have been increasing in size, this does not appear to be the case for our corpus of published grammars. By total page count, including appendices, the size of grammars does not increase

\footnotetext{
${ }^{8}$ For the division between what material is presented in the main body of the grammar and what is presented in appendices, we follow the authors' individual decisions (even if these do not prove consistent across grammars, with some authors including texts as a chapter and others including texts as appended material).
} 
over the time period covered by our corpus: the earliest reference grammar is van Driem 1987 at 565 pages ( 276 pages without appendices), while the second most recent grammar in the corpus is Schackow (2015), which has 603 pages (527 pages without appendices). If one counts only the chaptered content and excludes appendices, then the two largest grammars in our corpus are from 2015 (Schackow) and 2002 (Watters). Note that the fact that our corpus is made up not of dissertations but of published grammars, some of which were dissertations and some of which were published mid-career, likely affects issues of comparability of size.

\subsubsection{Numbers of chapters}

Our main interest is the meta-level organizational schemes underlying grammatical description, and we thus consider the number of chapters (and their titles) to be important. The corpus has grammars ranging from four chapters (Poudel 2006) to 21 chapters (Genetti 2007).

We find that, despite differences in size across the grammars of the corpus, there is no obvious relationship between the number of chapters and the length of the grammar: both Turin 2012 and Hari 2010 have 7 chapters, even though their page counts are 484 pages and 127 pages respectively, excluding appended material.

\subsection{The database}

The database built from our corpus is made up of two parts: a) classic metadata for the grammars (title, author, date, publisher/collection, number of pages, etc...) as well as information about past and current institutional affiliations of linguists, secondary affiliations (such as SIL), dissertation supervisor. This data allows us to keep track of the interrelations connecting linguists and possible influencing factors on the way they write grammars; $b$ ) complete tables of contents for all the grammars in the corpus, with unique identifiers for each titled chapter, section and sub-section, cross-referenced in such a way as to reveal where similar content is treated in the other grammars in the corpus. These cross-references essentially constitute a relational database, organized around basic linguistic concepts (types of word classes, grammatical categories, subfields of linguistics...), indexing the unique identifier of the relevant sections of each grammar where the topic is treated. While an examination of the tables of contents was primary in developing the database, we also used the textual content of the grammars in order to determine how certain topics were treated (see discussions in sections 4.1 and 4.2 , in particular).

\section{Feature organization across the corpus}

In this section, we look in detail at the tables of contents of the grammars and describe the structural patterns found in the data.

\subsection{Front matter/Back matter, recurring patterns}

Focusing on the tables of contents, a number of patterns which can be used to characterize the grammars become apparent, both in the organizational features and in the content.

Across the corpus, the grammars start with an introductory chapter presenting the context for the descriptive project and information about the language, its classification, its speakers. These chapters are most often called 'Introduction' or variations thereof ('introductory remarks', 'introductory chapter', 'introduction to X language'), but we also find first chapters with titles referring directly to the name of the language: 'The Dumi' (van Driem 1993), 'Les Hayu et leur langue' (Michailovsky 1988), 'The people and their language' (Watters 
2002). In Turin 2012, Chapter 1 presents 'The linguistic classification of the Thangmi', and is then followed by Chapter 2, 'The Thangmi ethnolinguistic context'. Apart from Turin 2012, only two other grammars in the corpus have a second chapter which presents the speakers (in both cases, following an Introduction in Chapter 1): Schackow 2015's second chapter is 'The Yakkha language and its speakers', while Gawne 2016's Chapter 2 is entitled 'The Lamjung Yolmo context'.

Following the introductory and sociolinguistic presentations, which make up the first chapter, or, as seen above, the first and second chapters, the next chapter serves to present the phonology of the language. This is a consistent feature across the corpus, and conforms to Mosel 2006b's "ascending" grammar type (from phonemes to clauses, with ever-increasing linguistic units). Note that the "descending" model promoted through the use of the 1977 Comrie \& Smith Lingua Descriptive Series questionnaire, whereby the grammar first presents syntactic features of the language before working down to smaller units, has not been taken up by any authors of the grammars in our corpus.

As concerns back-matter, all but three grammars in our corpus are accompanied by texts, which range from 7 pages (Kelly 2004) to 270 pages (Turin 2012). This concords with recommendations to this effect (Lehmann \& Maslova 2004, Mosel 2006b, among others). In most cases, texts are presented in an appendix to the grammar, but in the case of Rutgers 1998 and Turin 2012, the number of texts is substantial enough to warrant being collected into a distinct part of the grammar (for Turin 2012, a separate volume; for Rutgers 1998, a 'Part 2'). The grammars that stand out from the norm in terms of appended texts are Gawne 2016 and Watters 2002, both of which have texts in, respectively, the last and penultimate chapter of the grammar, thus bringing the presentation of texts into the grammatical description, rather than treating them as additional material. In the three grammars without texts (Ebert 1997a, Poudel 2006, Hari 2010), only one author makes explicit that there is a reason for the lack of texts: Ebert (1997a: 7) mentions that an accompanying volume of texts is forthcoming (later published in 2000).

While the inclusion of texts is a strong tendency across the grammars of our corpus, fewer of the grammars are accompanied by a glossary or word list. Both Michailovsky 1988 and Gawne 2016 include texts but no glossary or word list. Schackow 2015, which includes textual material, has no glossary but provides an index of grammatical formatives. Poudel 2006 and Ebert 1997a have neither texts nor glossaries. Watters 2002 adopts the same approach to the glossary as to the texts, assigning it to a distinct chapter within the grammar. The outlier in terms of text and glossary treatment is Hari 2010, which includes a glossary making up one of the chapters of the grammar but no texts.

In sum, 13 out the 18 grammars in the corpus provide glossaries or word lists, resulting in a meta-structure which does not conform as closely as one might expect, given current recommendations (such as Aikhenvald 2015: 6), to the "so-called Boasian trilogy" of grammar, glossary, texts $^{9}$ (Evans and Dench 2006: 10).

\footnotetext{
${ }^{9}$ It is interesting to note that this descriptive 'triptych' dates considerably further back than Boas: Smith-Stark 2009 discusses the 'trilogía catequística' that is made up of grammatical descriptions ('artes'), dictionaries ('vocabularios') and text collections ('doctrinas'), even though the latter were translation-based renderings of Catholic texts rather than autochthonous, in 16th century language descriptions from New Spain. He himself points out the parallel with the Boasian trilogy (2009: 471). Do note that the pieces of the trilogy were produced at different times and by different authors, although cross-references make clear that they were materials that built on each other, and it is therefore possible that the doctrinal texts served as the corpus for the grammar. From the second half of the 17th cent. we find all three parts of the trilogy published together in one volume (Otto Zwartjes, pc. May 2019).
} 


\subsection{Taxonomy of feature types}

Based on an analysis of the tables of contents of the grammars in our corpus, we propose a taxonomy of organizational principles applied by authors to the structure of their description. The chosen structuring schemes necessarily impact our understanding of the grammar, serving as they do as the lens into the language. Setting up a taxonomy of the types of schemes that are used allows us to identify the main variables that have an influence ${ }^{10}$. In order to better identify the structuring schemes of the corpus grammars, we only take into consideration the macro-level structure of the grammars, namely the top-level chapters. While the detailed content of each section is very interesting, especially in looking at the importance given to a specific topic or similarities between organizational schemes by different grammarians, they simply contain too much information for the purposes of establishing broad types, and we have resorted to using macro-level tables of contents. The types that make up this taxonomy are seen in Fig 1 below:

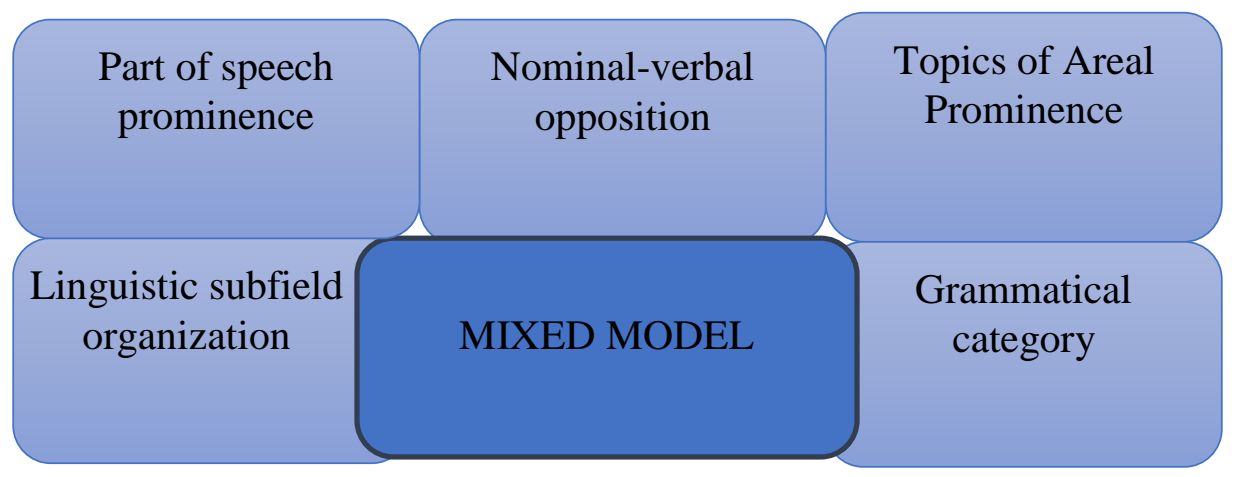

Fig. 1. Basis for structuring feature types

As will become evident below, these feature organization types are not employed exclusively across the grammars and in most cases, we see multiple types within a single grammar, resulting in the type labelled "mixed model" in Figure 1.

\subsubsection{Prominence of parts of speech}

For grammars of this type, the parts of speech feature prominently (but not necessarily dominantly) as an organizational framework. The eight major parts of speech recognized by the Western grammatical tradition (noun, verb, adjective, adverb, pronoun, preposition, conjunction, interjection; see Colombat \& Lahaussois, in press) are not always present, but the organization of each grammar has chapters for more parts of speech than just nominals and verbals. Genetti 2007 and Schackow 2015 are the two grammars in the corpus in which this feature is most prominent. In Genetti 2007, we find 'Nouns and noun morphology' (Ch. 4), 'Verbs and verb morphology' (Ch. 6), but also 'Personal pronouns, interrogatives, indefinites and demonstratives' (Chapter 5), 'Adjectivals' (Chapter 7), 'Quantifiers' (Chapter 8), 'Adverbials' (Chapter 9), and 'Particles and clitics of individuation' (Chapter 10). In Schackow 2015 we find, in addition to 'The noun phrase' (Chapter 5) and 'Verbal inflection' (Chapter 8), 'Pronouns, demonstratives, quantifiers, numerals, interrogatives' (chapter 4), and 'Adjectives and adverbs' (Chapter 6). This is not to say that word classes are not present in other

\footnotetext{
${ }^{10}$ The more obvious of these are the date and size of the grammars.
} 
grammars in the corpus, but when present, they occur lower down in the organizational hierarchy, as sections within larger chapters; Doornenbal 2009, for example, has a chapter on 'Other word classes' (Chapter 8), but his organizational scheme does not give the same prominence to parts of speech as we find in Schackow 2015 and Genetti 2007.

\subsubsection{Nominal vs. verbal opposition}

Grammars exhibiting the feature of nominal vs. verbal opposition are essentially organized around a binary opposition between nominal material and verbal material. ${ }^{11}$ Grammars with this opposition are distinct from those which are part-of-speech-prominent, though it is possible for a grammar to be characterized as having neither of the two features. An example of a grammar which shows a strong nominal vs. verbal opposition is Ebert 1997a, the chapter-level table of contents of which is reproduced below:

\begin{tabular}{l}
0 Introductory remarks \\
1 Phonology \\
2 The Verb \\
3 Nominals \\
4 Basic sentence pattern \\
5 Clause combining \\
\hline
\end{tabular}

Note that one particularity of this grammar, also found in Ebert 1997b, is that the chapter on the verb is ahead of that on the noun. The ordering of chapters in the grammars of the corpus will be discussed in section 3.3.

\subsubsection{Organization by linguistic subfield}

The traditionally core subfields of linguistics can also be used as an organizational scheme for grammars, with chapter titles such as Phonology, Morphology, Syntax. A good example of a grammar with this feature is Michailovsky 1988, with the following table of contents:

1. Les hayu et leur langue

2. Phonologie

3 Morphologie (1): structure du mot verbal

4. Morphologie (2) : structure du mot non verbal ; parties du discour

5. Syntaxe

The subfields of linguistics form the organizational basis for the grammar, the only additions being the introductory language orientation and ethnographic chapter (Chapter 1 ) and two appended texts.

It is interesting to connect this type of organizational scheme to its forebearers: Chapters on phonology and syntax have a long history, going back as far as the earliest grammars of the Western tradition. The treatment of morphology, while present in the very first Western grammars, was often in chapters on individual parts of speech, describing their 'accidents' (Lallot, in press; Colombat, in press). The term 'morphology' as applied to linguistics (as the German "Morphologie") seems to date back to Schleicher (François 2013).

\footnotetext{
${ }^{11}$ This binary opposition reflects the age-old prominence given to nouns and verbs in grammars, going as far back as Plato (see Colombat and Lahaussois, in press: 32).
} 
In his voluminous Compendium from 1861, there are only two large sections: Phonologie and Morphologie.

For a contemporary linguist, it seems that a structure based on subfields of linguistics most likely results from the organization of the curriculum of most linguistics departments into core courses reflecting this same division into subfields. Thus Nida's 1949 textbook "Morphology" was probably a significant, if indirect, influence on this 'subfield'-type of grammaticographical scheme.

\subsubsection{Structure highlighting areally-prominent features}

This type of scheme is in fact a sub-scheme, because it only concerns one or at most a few chapters of grammars of the relevant type. Grammars classified as highlighting areallyprominent features have at least one chapter which describes an areal feature of the language which is of particular interest for comparative work on the subgroup, family, or in the linguistic area. An example of this is an areally important nominalization pattern (Matisoff 1972, DeLancey 2002, Noonan 1997, Genetti et al 2008, among others), eventually given the label Standard Sino-Tibetan Nominalization ('SSTN') (Bickel 1999); because of the similar patterns found across Sino-Tibetan languages, the topic is typically treated prominently in grammars of languages of the family.

Another example of an areally-prominent topic which appears at the chapter level is Schackow 2015's chapter on 'The geomorphic orientation system' of Yakkha ${ }^{12}$. What is significant here is that the author has chosen to deal with the topic at the macro-level ${ }^{13}$ of the structure, rather than lower down in the chapter hierarchy (the same information might have been treated in sections of chapters as well), which is a strong indication of the importance accorded the topic in question.

A subcategory of this type of structuring scheme is that where the author is explicit about organizing the grammar according to a language-driven scheme, an approach that rose to prominence under Boas, giving prominence to the most interesting topics in the language. Genetti (2007:27) structures the Dolakha Newar grammar on the basis of the categories that emerge from the language and highlights the use of a functional analytical framework in which "[e]ach language is an examination in its own terms as opposed to being pushed into a 'universal' mold which does not do justice to its structure". This is echoed in Doornenbal's (2009:2) suggestion that "[e]very language deserves a description in its own terms. To try to apply foreign terminology to a language does not always clarify the issues". While these statements often refer to the use of terminology, the effects of such an approach can also be found in the layout of the table of contents.

Highlighting areally-important topics allows for comparative work, and these topics tend to be taken up by most authors in the corpus, even though not all of them will place the information in distinct chapters.

\subsubsection{Structure highlighting grammatical categories}

As with areally prominent features, the presence of prominent topics in linguistics (by which we mean grammatical categories, such as tense, aspect, but which can also extend to topics such as transitivity) in the table of contents of a grammar is a sub-scheme, rather than a

\footnotetext{
${ }^{12}$ Note that in Ebert 1997a's list of "most interesting features" of Camling, we find "the system of altitudinal terms, especially the grammaticalisation of altitudinal case markers." (1997a: 7)

${ }^{13}$ When we use the term 'macro' we mean at the highest levels of table of contents, either distinguishing the grammar from the glossary and texts, or distinguishing chapters.
} 
primary organizational scheme. We employ this feature type to identify grammars which have, at the chapter level in their tables of contents, topics that in other typologically different language areas can be found at a lower level of the hierarchy. An example of this is the presence of a chapter on tense and aspect (as found in Genetti 2007) in the chapter-level table of contents, when the information might have been discussed within the chapter on verbal morphology. The choice by the author to place these topics at chapter level can be explained in a number of ways, but regardless of the motivation for their structural position, the effect is that they have been given a distinct prominence within the grammar.

\subsubsection{Discussion of taxonomy and its significance for the corpus grammars}

Table 2 below illustrates the distribution of feature types discussed above across the grammars of the corpus.

\begin{tabular}{|c|c|c|c|c|c|}
\hline Author & $\begin{array}{l}\text { POS } \\
\text { prominence }\end{array}$ & $\begin{array}{l}\text { nominal vs } \\
\text { verbal }\end{array}$ & $\begin{array}{l}\text { linguistic } \\
\text { subfield } \\
\text { organization }\end{array}$ & $\begin{array}{l}\text { areal feature } \\
\text { prominence }\end{array}$ & $\begin{array}{l}\text { grammatical } \\
\text { categories }\end{array}$ \\
\hline $\begin{array}{l}\text { van Driem } \\
\text { (1987) }\end{array}$ & & $x$ & & & $x$ \\
\hline $\begin{array}{l}\text { Michailovsky } \\
\text { (1988) }\end{array}$ & & & $x$ & & \\
\hline $\begin{array}{l}\text { van Driem } \\
(1993)\end{array}$ & & $x$ & & & $x$ \\
\hline Ebert (1997a) & & $x$ & & & \\
\hline Ebert (1997b) & $x$ & & & & \\
\hline Rutgers (1998) & & $x$ & & $x$ & $x$ \\
\hline Watters (2002) & $x$ & & & $x$ & $x$ \\
\hline $\begin{array}{l}\text { Hildebrandt } \\
\text { (2004) }\end{array}$ & & $x$ & $x$ & & \\
\hline Kelly (2004) & & $x$ & $x$ & & \\
\hline Poudel (2006) & & & $x$ & & \\
\hline $\begin{array}{l}\text { Doornenbal } \\
(2009)\end{array}$ & & $x$ & & & $x$ \\
\hline Hari (2010) & & & & $x$ & \\
\hline King (2010) & & $x$ & & & \\
\hline Regmi (2012) & $x$ & & $x$ & $x$ & \\
\hline Turin (2012) & & $x$ & $x$ & & \\
\hline Genetti (2014) & $x$ & & & $x$ & $x$ \\
\hline Shackow (2015) & $x$ & & & $x$ & $\mathrm{x}$ \\
\hline Gawne (2016) & & $x$ & $x$ & & \\
\hline
\end{tabular}

Table 2. Distribution of feature types according to grammars

While a few of the grammars in the corpus fit into a single category from the taxonomy above, in many cases (11/18), the grammars were coded as fitting more than one feature type and are henceforth referred to as mixed-type grammars.

It is precisely due to the mixed nature of most of the grammars that it is difficult to trace the influence of the organizational schemes on the impact of the grammars in 
transmitting an understanding of the language. If we consider missionary grammars of the Renaissance with their traditional grammar schemes (based on the parts of speech), any deviation from the norm was significant. In a modern grammaticographical setting where there is no single template, it is more difficult to identify the significance of what look like combinations of schemes, because there are so many possible explanations for their inclusion. Attempting to truly tease apart the rationale behind a structuring scheme would require lengthy interviews with the grammarians, but we can identify possible influences:

1) topics of interest to the linguist him/herself; 2 ) influence of academic/intellectual mentor (either explicit or through inspiration from topics that mentors have worked on); 3) topical trends: these are explored in section 4 for two topics, and are an interesting theme to consider further. Rice (2006) discusses the impact of formal theoretical work on description and grammar-writing, with examples drawn from her influences on her work on whquestions, complementizers and intransitive verbs 4 ) the inherent features of the language (it may, for example, be unthinkable to not include a chapter on elevational deixis, at the toplevel of the grammar, for a language where this is relevant, as this structural organization highlights the special features of the language.

The largest division is into POS-prominent or nominal-verbal opposition schemes, in other words, tracking how each grammar deals with word classes.

In essence, the grammars that do address word classes through dedicated chapters tend to be the more thorough grammars, based on large corpora; but this is not necessarily the case: van Driem's student grammars, which are substantial in size, do not elaborate on word classification, focusing their efforts on nominal and verbal morphology, with a briefer treatment of the former and a more involved treatment of the latter. This could, however, be colored by the fact that verbal morphology of Kiranti languages - the focus of many of van Driem's students-is particularly complex. Van Driem-inspired grammars thus understandably spend considerable time on the morphological make-up of indexes, breaking down portmanteaux into component parts and providing a great many verbal paradigms.

\subsection{Chapter ordering}

In addition to feature types, another question concerns the order of chapters in individual grammars and what this reveals about what the linguist considers to be the most important features of the language. In Ebert's grammars (1997a, b), the chapter on verbs is positioned before the chapters on nouns. A comment in Ebert's introduction suggests that the ordering reflects the importance Ebert assigns to the various parts of the grammar:

"The most interesting features, to my mind, are a) the complex verbal paradigms, together with the restructuring in the SE-dialect mentioned above; b) the semantic marking of participants on the verb, i.e. the lack of "agreement"; c) the systematic head marking, with most information coded on the verb (even in subordinate clauses, which is rather remarkable in the area); d) the system of altitudinal terms, especially the grammaticalization of altitudinal case markers." (Ebert 1997a: 6)

In this sense, the order of topics in the Camling grammar reflects the same approach as Aikhenvald's (2015:16) suggestion that "[a] linguist may choose to put the most exciting part of the language more upfront." 
Poudel 2006's Chapter 3 is on the Lexicon, immediately followed by a very long chapter on Syntax. This ordering may seem unusual in the sense that as a general rule lexical matters are relegated to the appendix or a late chapter within the grammar, when present at all. The explanation for the ordering of the chapter on the Lexicon here is probably to be found in the fact that Poudel uses it, after an initial section listing words of TB and loan origins, to present morphological processes (affixation, compounding, reduplication, conversion).

In Genetti 2007, the order of the main chapters featuring word classes is the following:

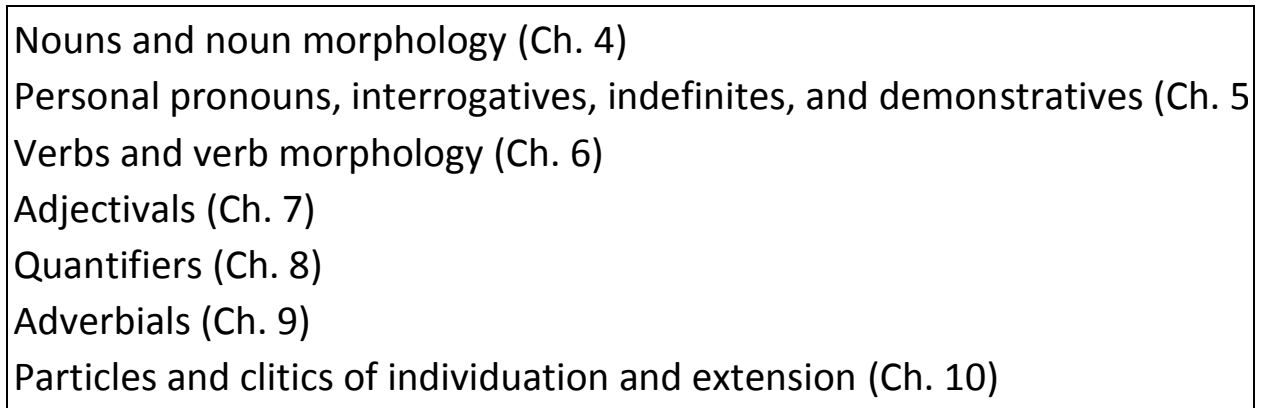

On the basis of the general trends across the grammars in the corpus, it is unusual to find adjectivals following the chapter on verbs, especially considering that they are typically described within a chapter on nominal morphology across the rest of the corpus. In the case of the grammar of Dolakha, this choice is justified by Genetti, who elsewhere has described the liminal nature of the "hybrid category" of Adjectival verbs (Genetti 2014: 124-126), which constitute the first part of the chapter on Adjectivals.

\section{A closer look at selected topics}

In this section, we use the database, supplemented by the text of the relevant sections of the grammars, to look at two topics of areal importance.

One of the questions we which to address through this focus on two topics of interest to the linguistic area is:

a) how the organizational scheme chosen by a grammarian affects the inclusion of linguistic material

b) how these decisions of what to include potentially affect work by typologists using the grammars in question to explore language diversity and variation, in turn influencing future descriptive linguists who turn to typological studies to write (temporally) relevant grammars

c) how typologically diverse languages from a same area conform (or not) to a regional descriptive template (resulting sometimes in empty categories in grammars, see section 5)

The first topic that we will look into is a combination of two marginal word classes, namely ideophones and interjections, often left out from grammars. The second topic is evidentiality, with some comments on mirativity. The reasons for selecting these two topics are different, but in both cases, they tie in with tracing the influence of seminal papers on the topics in a TB language and seeing how that influence spreads (or not) across the grammars of the corpus. The discussions also highlight the fact that different authors use terminology rather differently, with a potential impact on the interpretation of the data they present and the possibility of using them for comparative purposes. 
In order to identify how these topics are treated in the grammars, we used the database to identify whether topics are given chapter- or section-status, and if so, what larger part of the grammar they fall within. In addition, we looked at the text of the grammars, using the index and searching manually for references to the concepts or related phenomena. The rationale for the double approach was to determine the extent to which the presence of material discussed in the text of the grammar could be identified through the table of contents.

\subsection{Ideophones and interjections}

Both ideophones and interjections are marginal categories (although for perspective on the marginality of the former, see Dingemanse 2018), though for different reasons, and as result of this status, they are not systematically described in grammars. Ideophones are areally very much present, and are frequently used in the contact-language Nepali.

Major typological work on ideophones appeared in 2001 with a volume edited by Voeltz and Kilian-Hatz; earlier work under the topic of sound symbolism (such as Hinton et al 1994) might have escaped the notice of descriptive linguists, as it is not obviously associated with a category that can be tied in with a grammatical description. As far as TB languages of Nepal are concerned, ideophones are discussed in a 1997 article on Bantawa by Winter and Rai (the title refers to Verbal adjuncts and not ideophones), in a 2002 article by Caughley on Chepang, and in a 2005 article by Rai, Bickel et al. describing the phenomenon in Bantawa and Chintang, with the latter two articles using the term ideophone in their titles. ${ }^{14}$

As a result of the available literature focusing on specific languages, there seems to be a geographical bias in the treatment of ideophones in the grammars in our corpus: for languages closely related to Chintang, Bantawa, Chepang, they are described, while for less closely related languages, they are most often omitted from grammatical descriptions. The consequence of this omission is that a typologist wishing to study ideophones from a comparative perspective might take the areal distribution to be significant. For Kiranti, for example, ideophones are only described for Western languages, making it appear that the category is only present in one part of the subgroup. In fact, this is a result of grammaticographical choices by linguists (Lahaussois 2017).

Interjections present quite a different situation. Because of their non-participation in morphosyntactic operations, they are often left out of the works in our corpus, insofar as the grammatical descriptions often focus on morphosyntax. Yet as a historically identified part of speech in the Greco-Latin grammaticographical tradition, they are likely to be included in grammars using a part-of-speech prominent structuring scheme; this is all the more the case if the linguist has a missionary affiliation (Lahaussois 2016).

As far as our corpus is concerned, there are no major typological publications that appear to have affected the presence or absence of interjections in the grammars we have surveyed (despite a 1992 Journal of Pragmatics issue devoted to interjections which features descriptive articles, such as Ameka 1992). There does however appear to be a relationship between the size of the grammar and the presence of a section (or at least mention) of

\footnotetext{
${ }^{14}$ Ideophones are also discussed in a more recent article (Lahaussois 2017) which postdates the grammars in our corpus. Considering the recent surge of interest in the topic (Haiman 2018, Dingemanse 2018, Akita and Pardeshi 2019), it is to be expected that more articles on how the category manifests in the Himalayas will soon find their way to print.
} 
interjections; their marginality suggests they will come up in more comprehensive grammars but be considered non-essential in more compact grammars.

Eight (of the 18) grammars in our corpus mention neither ideophones or interjections, nor do they describe anything that approaches the phenomenon. These grammars are, in chronological order, van Driem 1987, van Driem 1993, Ebert 1997a, Rutgers 1998, Hildebrandt 2004, Kelly 2004, Poudel 2006, and Hari 2010.

The van Driem structural scheme is quite distinctive: nominal morphology vs individual chapters on verb morphology. As a result, there is no obvious place in which to discuss verb phrase constituents such as adverbs ${ }^{15}$, and therefore ideophones. The impact of this is significant, because of van Driem's influence in the field: through his role heading a large-scale grammaticographical effort, anyone who works on Nepal will have encountered his grammars or those of his students (many based on the same template); statistically, it will therefore seem like adverbs and ideophones are non-existent in languages from this part of the world, which is not true in the least.

At the opposite end of the spectrum are the grammars that include both ideophones and interjections (or related phenomena, even if using different terminology), and give them chapter-or section-heading status, so that the terms appear in the table of contents of the grammars. These are Watters 2002, Doornenbal 2009 and Schackow 2015.

There are also grammars that feature just one of the two topics at the chapter- or section-heading level: Ideophones (but not interjections) are discussed at the section-heading level in Turin 2012 (in a section entitled 'Adjectives as onomatopoeic adjectives') and in Regmi 2012. Interjections are given section-heading in Gawne 2016. Other grammars mention ideophones or interjections in the text, but do not devote a chapter or section of the grammar to the word class.

Looking at the size of grammars which include ideophones, interjections, both or neither, there indeed seems to be a connection between the comprehensiveness of the grammars and their treatment of marginal topics: the grammars discussing both terms in sections or chapters are among the largest in the corpus. The grammars discussing neither are among the shortest in the corpus.

In terms of the influence of the scientific literature on the description of the categories, it must be noted that the grammars that accord a chapter or section to ideophones were all published after 2002, in other words after the appearance of the 2001 Voeltz and Kilian-Hatz book that brought ideophones to the fore for descriptive work in a nonAfrican context (where the description of ideophones has been much more systematic, and from the 1930's on, despite some terminological confusion and the early use of the label interjection; see Dingemanse 2011).

In some cases, literature on closely related languages will result in the description of a category, even if the grammar is short. Regmi 2012 only contains 161 pages, but describes a variety of Chepang, a language for which Caughley 2002 describes ideophones. Schackow 2015 and Doornenbal 2009 both have sections on ideophones (given an alternative term in the latter: mimetics and paralexemes), and describe languages closely related to or for which significant articles on ideophonic lexemes have been published (Winter and Rai 1997, Rai et al 2005). Only Watters 2002, describing Kham, and Turin 2012, describing Thangmi, are not

\footnotetext{
${ }^{15}$ Adverbs are discussed in the text of the two van Driem grammars in the corpus, and found in examples and in the glossary, but no section is devoted to them. This stands in contrast to the treatment of adjectives, which have a section in the chapter on Nominal morphology.
} 
closely related to such languages, but in both cases, they are very large and comprehensive grammars.

The only grammar with a section on interjections but not ideophones (of our two marginal categories) is Gawne 2016. Even though it is a relatively short grammar, at 160 pages, and entitled a "sketch grammar", the section on interjections is probably a result of the choice to use a part-of-speech prominent organizational scheme for the layout.

\subsection{Evidentiality}

The marking of what we term evidentiality, the source of a speaker's or participant's knowledge, or kinds of knowing (Floyd et al 2018) has long been closely associated with TB languages. Woodbury 1986 on the Sherpa evidential system in particular highlighted the research of Hale (1980) and his discussion of the conjunct/disjunct evidential system of Kathmandu Newar.

Cross-linguistic interest in evidentiality gained prominence in the early 1980 s with the publication of 'Evidentiality: The linguistic coding of epistemology' (Chafe \& Nichols 1986) but interest waned somewhat over the next two decades. The publication of 'Evidentiality' (Aikhenvald 2005) came early in a resurgence in crosslinguistic work on evidentials and evidential systems, with several recent volumes, including 'The Oxford Handbook of Evidentiality' (Aikhenvald 2018), and 'Egophoricity' (Floyd et al 2018).

There have also been several publications focusing specifically on evidentiality in TB languages (Gawne \& Hill 2017) and those of Nepal (Caplow 2017, DeLancey 2018, Hargreaves 2018, Kelly 2018). These papers have arisen from different theoretical positions and there has been considerable discussion and debate regarding what constitutes different kinds of evidentiality. In part this derives from the fact that evidential systems in TB languages are often closely tied with the marking of epistemic modality. In addition, these discussions also derive from the different terminology used by researchers attempting to explain the same or very similar phenomena, such as the use of the terms 'EGO', and 'egophoric' to mark the same phenomena. The term 'egophoric' was first used to describe the grammaticized marking of conscious personal experience (Tournadre 1992; 1994) as was EGO (Garrett 2001) and this has generally been analysed as part of the language's evidential system, marking differences such as between a speaker's personal knowledge and knowledge gained externally. While we see in our corpus some of the trends in terminology that reflect the broader linguistic debates around what to call different kinds of speaker or participant knowledge, the terms 'evidential' or evidentiality' are used in all grammars in our corpus that discuss these forms. Grammars in the corpus that report at least one evidential category in the text of the grammar number 13 , with ten of them assigning evidentials a section- or sub-section level heading. While evidentials are widely attested in the grammars of the corpus, is not possible to determine from the table of contents what obligatory status they have in the languages that are reported to employ them. Five grammars in the corpus do not report on evidentials at all (van Driem 1987, 1993, Ebert 1997a, Ebert 1997b, Michailovsky 1988). In some of the grammars reporting evidentials the information is contained within other sections or there are further subsections either laid out on the basis of the language form of the evidential (such as Kelly 2004, '4.5.3.1 The evidential i') or of the function of the evidential (Watters 2002, '13.4 The mirative'). These sections and sub-sections in the tables of contents are likely to reflect the author's perception of the relative importance of evidential marking in the target language. However, such a focus on form versus function doesn't allow for easy cross-language comparison on the basis of tables of contents. Even assessment of function can be less than clear if the terminology differs, for example Rutgers 
(1988) has sub-sections on 'New awareness' and 'Probabilitive', while Schackow (2015) gives both the function and the form as 'The probability particle ?lo'. A broader separation of evidentials is given by Regmi (2012) who presents categories of 'Direct evidentiality' and 'Indirect evidentiality'. One more finegrained approach, not seen in any of the corpus grammars, would be to focus on the semantic features often associated with evidentiality and to categorize these, for example: visual, sensory, assumptive, inference, quotative, and reported speech evidential.

Seen together across different layouts of tables of contents the presence and absence of different sections highlight patterns of similarity and diversity across the Tibeto-Burman language area reflected in these structural schemas. Five grammars in the corpus do not report on evidentials at all (van Driem 1987, 1993, Ebert 1997a, Ebert 1997b, Michailovsky 1988). In some of the grammars reporting evidentials, there are further subsections either laid out on the basis of the language form of the evidential (such as Kelly 2004, '4.5.3.1 The evidential i') or of the function of the evidential (Watters 2002, '13.4 The mirative').

As mentioned above, evidential systems and epistemic modality are often closely tied in TB languages. This is evident in our corpus. For example, seven grammars have a section on epistemic modality, either interrelated with evidentiality (Regmi 2012, Hari 2010, Gawne 2016, Kelly 2004, Schackow 2015) or separate but mentioning evidentiality (Doornenbal 2009, Watters 2002). The remaining grammars all mention epistemic modality without discussing evidentiality.

One further domain in which the grammars in our corpus report evidential markers and epistemic markers is when presenting morphological markers of 'reported speech' and 'mirativity'. Reported speech is the marking of 'hearsay' or 'quotation' through the use of a grammatically encoded evidential. Reported speech has its own section in two grammars in our corpus (Gawne 2016 and van Driem 1993, the latter using this term but for a construction which is not evidentiality) and is mentioned in 14 of the grammars (with no discussion in van Driem 1987, Ebert 1997a, Ebert 1997b, Michailovsky 1988).

Mirative is a grammatical category encoding a speaker's surprise or lack of preparedness regarding information. Some researchers consider miratives to be a separate category from evidentials (De Lancey 2012) while others suggest the category is ill-conceived and mirative markers are largely evidential (Lazard 1999, Hill 2012). Originally described by DeLancey (1997) for Lhasa Tibetan, the term 'mirative' is mentioned in nine grammars in the corpus, with the term in a section heading of four grammars (Schackow 2015, Rutgers 1998, Watters 2002, Doornenbal 2009). Given the variable status of mirativity in the field, it is not surprising that we see its use in different ways across the grammars. Schakow 2015 has a chapter heading 'Epistemic, evidential and mirative markers', and Doornenbal 2009 discusses miratives within a section on 'Epistemic and Modal Particles'. Use of this term highlights an interesting issue with relation to the discussion of interjections and ideophones, namely how do the expectations of researchers, on the basis of descriptions of other related languages, affect what is included in a grammar. This is important to note, when we consider comments by Gawne (2012: 80) who writes “...the perceptual evidential forms in Lamjung Yolmo are not grammatical miratives" and Watters (2002) who writes "Kham lacks most evidential categories found in other Bodic-type languages" (Watters 2002: 4), both choosing to mention the absence of a category which a reader might expect to find in the grammar. It is also important to note that much of the material in the target grammars is based on elicited data, with the addition of further genres in some grammars, e.g. narrative, expository and conversational language use. Crosslinguistic studies have shown some variability in evidential 
use across different genres (Mushin 2013) which may have consequences for the prominence and organization of evidentials (and other topics) in the grammar.

In summary to this section on evidentials and other related grammatical categories, and interjections and ideophones across the grammars of our corpus, we suggest that several factors are of importance in how these are dealt with: a) the size of the grammar, particularly when it comes to marginal categories which are peripheral to core morphosyntax; $b$ ) the language being described, and whether closely related languages are featured in articles on the given topic ; c) the structuring scheme, with a part-of-speech prominent layout or a chapter or section on the topic; d) the year of publication of the grammar, as suggested by the fact that all the grammars that mention ideophones date from after the publication of the Voeltz and Kilian-Hatz (2001) volume on ideophones in the world's languages, and a number of articles about ideophones in the languages of Nepal, and the use of the term mirative appears in all grammars after the publication of the DeLancey (1997) article.

\section{Influences on the organization of grammars}

In this section, we look into potential motivations for how grammars have been shaped: the influence of mentors and peers, and of the broader linguistic literature.

\subsection{The influence of mentors: a look at what is revealed by mentor-student pairings of grammars in the corpus}

One external influence on the approaches to grammar writing and structural organization comes from the pedagogical influences on grammar-writers, in particular the influence of a mentor or PhD supervisor. In the acknowledgements section of several of the grammars in our corpus the linguists name supervisors, mentors, and people who have been influential in the development and writing of the grammars. In the following series of figures, we lay out a selection of relationships from the grammars in our corpus highlighting connections between linguists across different generations and potential influences. ${ }^{16}$

Employing a family tree metaphor, the following figures show that the chain of influence in grammar writing runs from the parent tier down to the next generation and in some cases to additional generations of linguists.

\subsubsection{The Leiden school}

George van Driem (originally at Leiden University, currently at Bern University) founded the Himalayan Languages Project ${ }^{17}$, which produced a number of descriptions of languages of the Trans-Himalayan area. Of the grammars within our corpus that stem from this project, van Driem wrote the grammars of Limbu (1987) and Dumi (1993) and his students, the grammars of Yamphu (Rutgers 1998), Dhimal (King 2009), and Thangmi (Turin 2012).

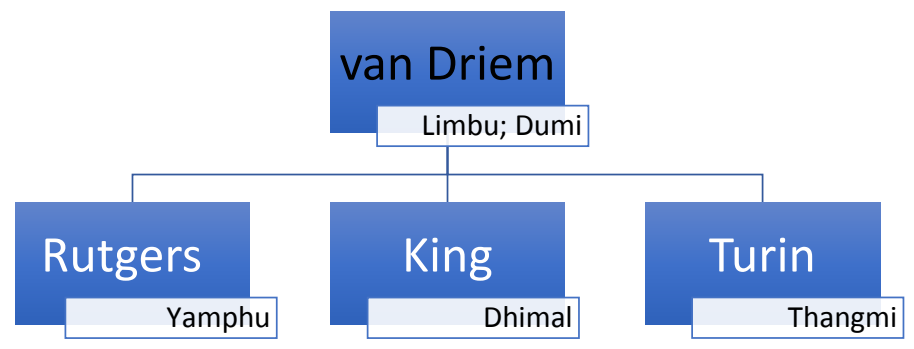

\footnotetext{
${ }^{16}$ Each of the clusters is named after the university where its 'genitor' taught and influenced their first generation of students in this study.

${ }^{17}$ http://www.himalayanlanguages.org/himalayan_languages_project
} 
Figure 2. van Driem's influence across multiple grammars

The original Leiden grammars, while not identical in layout, are shaped by a similar organizational scheme. After introductory material and a chapter on phonology, there is a chapter on nominal morphology, which is followed by a number of chapters dealing with different aspects of verbal morphology. This can be seen in Table 3, which shows the tables of contents of van Driem 1987 and van Driem 1993. One result of the structure is that, while adjectives and other nominal elements are discussed in the section on nominal morphology, the breakdown of verbal topics into distinct chapters does not leave any obvious section in which to discuss adverbials.

\begin{tabular}{|l|}
\hline 0 Introduction \\
1 Phonology and phonetics \\
2 Nominal morphology \\
3 The verbs 'to be' \\
4 Morphemic analysis of the \\
simplicia \\
5 Aspect and aspectivizers \\
6 Mode \\
7 Gerunds and periphrastic tenses \\
8 Other verbal constructions \\
9 Subordination \\
10 Causatives and ergativity \\
Appendix I Texts \\
Appendix II Paradigms \\
Appendix III Limbu-English glossary \\
Appendix IV Anthology of Kiranti \\
scripts \\
\hline
\end{tabular}

1 The Dumi
2 Phonology and Phonetics
3. Nominal Morphology
4 Conjugations of the verb
5 Morphology of the Simplicia
6 Aspect and Aspectivizers
7 Causatives and Transitivity
8 Perfect tenses
9 Other verbal constructions
Appendix 1 Texts
Appendix 2 Paradigms
Appendix 3 Dumi-English glossary
Appendix 4 Plates

Table 3. van Driem 1987 Limbu grammar (left) and van Driem 1993 Dumi grammar (right)

It is noteworthy that van Driem is the author of a 2007 "manifesto" on grammarwriting ${ }^{18}$, in which he advocates that languages be described in their own terms--this statement is in the first sentence of his text--and not forced into a template imposed by grammatical categories from other languages (Note that van Driem is quite strongly opposed to the Lingua Descriptive Series questionnaire, 2007: $119 \mathrm{ff}$.). His message is clear: "Let the language itself be your guide. Let its structure determine the structure of your grammar." (ibid 121.)

We find in the grammars of van Driem's students similarities with the scheme employed in the van Driem grammars. This is to be expected by virtue of the fact that the grammars produced in Leiden are all of languages related to Limbu and Dumi, yet the similarity in the organizational principles of the grammars appears to go beyond what is simply a result of the relatedness of the languages. In Rutgers 1998, the bulk of the grammar, after chapters on phonology, morphology, and morphophonology, is devoted to aspects of

\footnotetext{
${ }^{18}$ As mentioned in footnote 1 "The Dallas Manifesto was first presented at the Grammar Writing Symposium organised by the Summer Institute of Linguistics at Dallas on the 19th of October 2002."
} 
verbal morphology, treated in distinct chapters: 'The finite verb' (Ch 5), ' Auxiliary verbs' (Ch 6), ' Non-finite verbs' (Ch 7), 'Tense and periphrastic constructions' (Ch 8 ).

Turin 2012 has some identifiably shared features with the van Driem grammars: a chapter presenting simple verbs is entitled 'Morphology of simplicia' (the same term is found in both van Driem 1987 and van Driem 1993), and another chapter, 'Other verbal constructions and morphosyntax' (compare to van Driem's grammars' 'Other verbal constructions').

A major difference, in the case of Turin, is that all the verbal information is grouped under the two afore-mentioned chapters, rather than across a number of separate chapters, as with the van Driem (and Rutgers) grammars. It is considerably more difficult to detect the influence of van Driem in King 2009, which groups all the information to do with verbal morphology under a single chapter ('Verbal morphology'). A look at terminological choices makes the connection between van Driem and King more apparent however: in our entire corpus, the term 'adhortative' (instead of the more traditional 'hortative') is shared only by van Driem, Turin and King. The matter of the influence of van Driem on his students is thus not transparent but is suggested through terminological and, in some cases, structural choices. ${ }^{19}$ The heritage of the Leiden school will be better documented through a larger corpus with additional grammars by his students.

\subsubsection{The Oregon school}

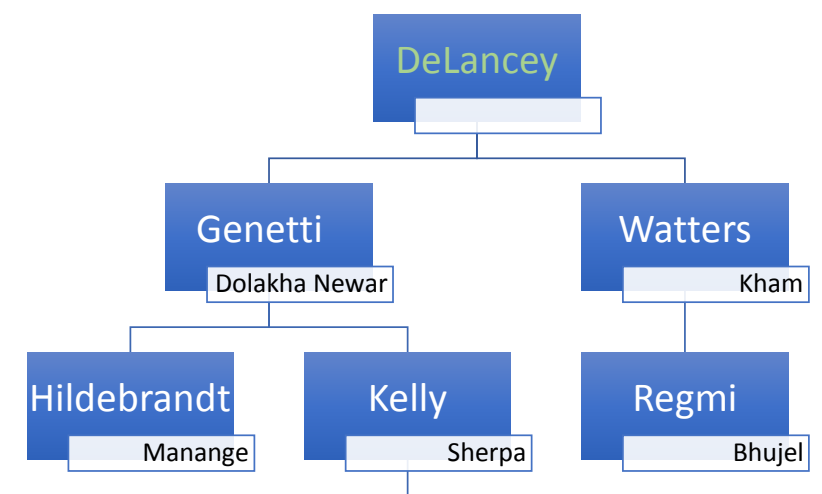

\section{Gawne}

Yolmo

Figure 3. DeLancey and three generations of influence

Figure 2 above shows a grouping of linguists with grammars in our corpus across multiple generations. DeLancey, at University of Oregon, Eugene trained two of the grammarians from our corpus (Genetti and Watters), who in turn went on to train or advise others. As a linguist teaching at Tribhuvan University in Kathmandu, Watters was influential in the training of Regmi, who wrote a grammar of Bhujel (Regmi 2012). At the University of California, Santa Barbara, Genetti trained two of the linguists in our corpus who wrote sketch grammars of Manange (Hildebrandt 2004) and Sherpa (Kelly 2004). The tree extends to another generation, with Kelly having trained Gawne at the University of Melbourne.

\footnotetext{
${ }^{19}$ The foreword of King's grammar, written by van Driem, makes mention of King's independence, physical and financial (2009: ix), when he worked on his dissertation, perhaps partly explaining his rather different grammaticographical style.
} 
As Delancey is not part of our corpus, we will focus on the next generation of grammars, and specifically the Genetti line. It should be noted that Genetti's and Watters' grammars are the second and third longest grammars in our corpus, in terms of page count of grammatical content (excluding appendices), and both are "mature" grammars, published some time after their authors obtained their degrees and began training other scholars.

\author{
Genetti 2007 \\ 1. Context \\ 2 Segmental phonetics and phonology \\ 3 Prosody \\ 4 Nouns and noun morphology \\ 5 Personal pronouns, interrogatives, indefinites, and demontrastives \\ 6 Verbs and verb morphology \\ 7 Adjectivals \\ 8 Quantifiers \\ 9 Adverbials \\ 10 Particles and clitics of individuation \& extension \\ 11 Noun-phrase structure \\ 12 Clause types \\ 13 Grammatical relations \\ 14 Constituent order \\ 15 Clause-level syntactic constructions \\ 16 Tense and aspect \\ 17 Nominalization and related structures \\ 18 Complementation \\ 19 The participial construction \\ 20 Adverbial clauses \\ 21 The sentence: prosodic and syntactic structuring
}

Grammars written by the next generation of linguists mentored by Genetti share a very similar structure: each has just five chapters with similar chapter headings, with chapters introducing the language and its phonetics and phonology, chapters on the 'Noun Phrase', 'Verb Phrase' and 'Clause Combining/ Clause \& Sentence Structure', with no further breakdown of categories at the chapter level. Extending the tree metaphor used to describe the relationships, we thus have two branches of our family with the same features, suggesting that they come from the parent and are the result of guidance from Genetti.

There is, however, an interesting thing to note about Genetti's grammar: it was published after that of her students, and thus had no direct influence on them, except insofar as Genetti's ideas about language and grammar-writing were orally passed on to students and were certainly well-established at the time (and had seen publication in the form of her 1994 monograph on Dolakha Newar ${ }^{20}$ ). It is noteworthy that when we attempt to connect the

\footnotetext{
${ }^{20}$ It is interesting to note how much closer Genetti's dissertation (Genetti 1990) is to the organizational structures seen in Hildebrandt and Kelly's grammars: the chapters are Introduction, Phonology, Morphology of the noun phrase, Morphology of the verb, The sentence. Contrast this to Hildebrandt (Introduction, Manange phonetics and phonology, The Manange noun phrase, Morphology of the Manange verb complex and the clause, Clause combining strategies in Manange) and to Kelly (An introduction to Sherpa, Phonology, Morphology of the noun phrase, Morphology of the verb phrase, Clause and sentence structure).
} 
grammars in the corpus with grammar-writing and field manuals, as we do in section 5.2, Genetti's grammar shares much of its structure with the "Possible outline for a balanced grammatical description" in Payne 2014. Looking at the dates for the two publications, Genetti's grammar precedes Payne's grammaticographical article; additionally, as it won the ALT Gabelentz best grammar award, Genetti's grammar would have attracted attention, and it seems that it may well have influenced Payne's idealized grammar outline (2014: 104). Note however that Payne lays out his principles for grammar organization in an earlier publication (2007: 140-141), even though this is much more schematic than the detailed 2014 detailed proposal (2014: 104-108).

Turning to Gawne's grammar of Yolmo, we see similarities with her advisor Kelly's Sherpa grammar with chapters on 'Noun Phrase', 'Verb Phrase' and 'Clause Structuring' as well as the addition of a further chapter on 'Parts of Speech'. The similarities are clearer when one goes deeper into the structure of the grammars, with entire sections titled and ordered in the same way. The adoption of the "Kelly model" by Gawne confers the advantage of facilitating the comparison of data from the two languages.

\subsubsection{The Zurich school}

The next schema has three generations of linguists, only two of which are in our corpus. The middle generation is not represented.

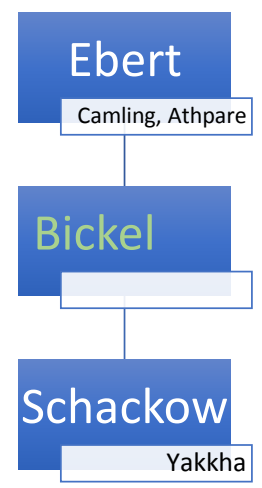

Fig. 4 Ebert's influence

Ebert, the author of grammars of Camling and Athpare, supervised Bickel, who has written extensively on the grammar of TB languages and the typology of languages of Nepal (among others) but has not written a reference grammar. Bickel advised Schackow who wrote a grammar of Yakkha (2015).

The following figures show the tables of contents for Ebert's two grammars and Schackow's grammar.

0 Introductory remarks

1 Phonology

2 The Verb

3 Nominals

4 Basic sentence patterns

5 Clause combining

Ebert 1997a 'Camling'
0 . Introductory remarks

1. Phonology

2. The verb

3. Nominals

4. Adverbs, particles, and clitics

5. Basic sentence patterns

6. Clause combining

Appendix A Verbal paradigms 
Appendix A1 Intransitive paradigm

Appendix A2 Transitive paradigm

Appendix $B$ Verbs according to stem finals

Appendix C Texts

Appendix D Glossary

Ebert 1997b 'Athpare'

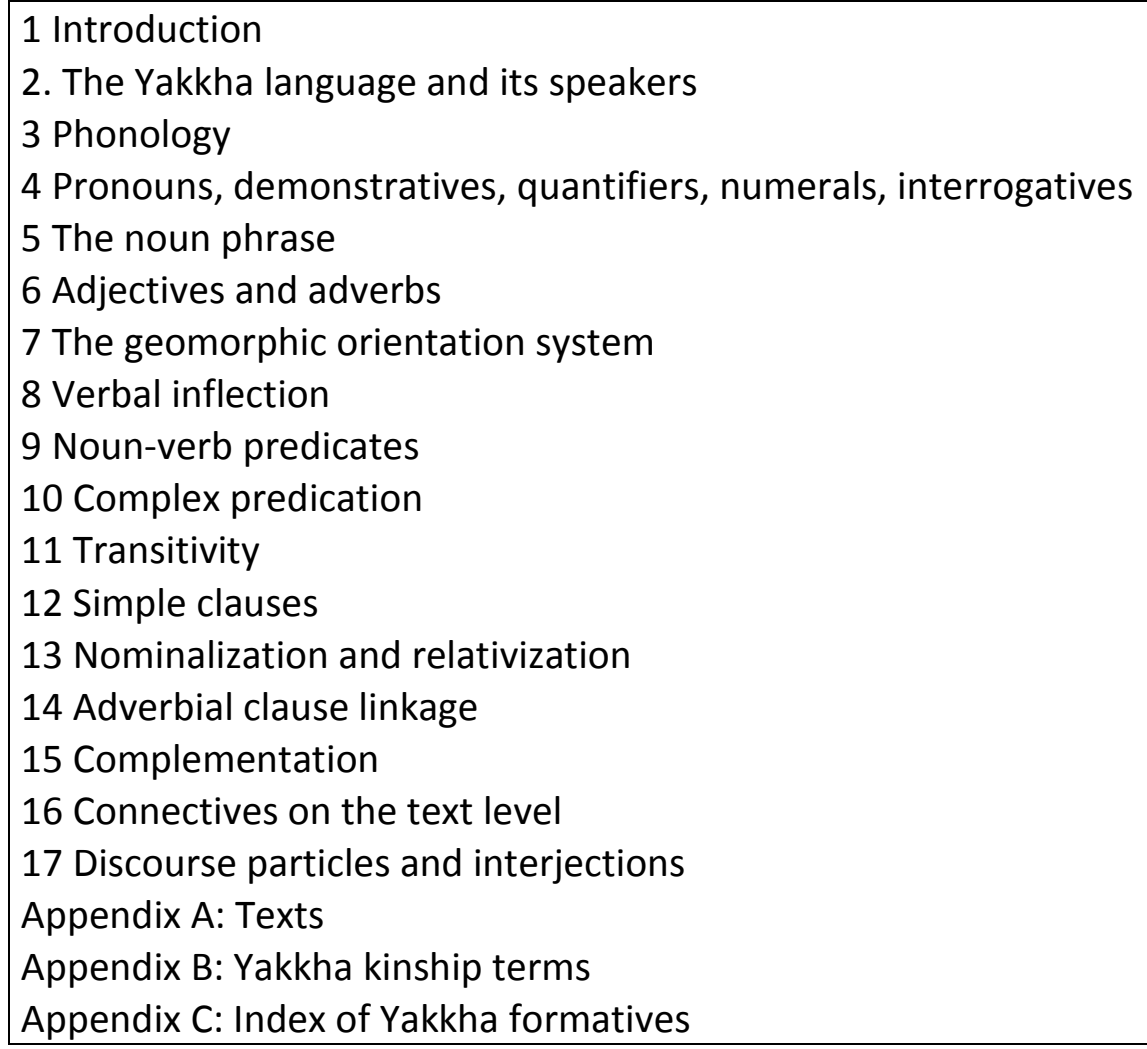

We see very little transmission from Ebert to Schackow, looking at the top-level tables of contents shown in the figures above. Schackow's grammar is remarkably comprehensive, whereas Ebert's are considerably shorter and do not aspire to describe the languages in as complete a fashion. A look at details, however, reveals some influences that might otherwise be overlooked, such as can be found in the schematic presentation of verbal paradigms. Ebert's verbal paradigm follow a matrix style (Lahaussois, in press), and while she claims to use the presentation style adopted by van Driem (Ebert 2007: 30), her paradigms are in fact innovative in an interesting way: in addition to a matrix of agents in the vertical axis and patients in the horizontal axis, resulting in individual cells for each agent > patient scenario, she also includes intransitive data in the paradigm, as an additional column on the right-hand side of the transitive data. Both Bickel (eg. 2003: 551-552) and Schackow (2015: 218) assemble verbal paradigms with intransitive forms alongside transitive, positioned as in Ebert's presentation. This presentation style is not found elsewhere in our corpus, and suggests an influence that has spread across three generations.

Finding evidence of the specific influence of Bickel on Schackow's work is difficult, especially without being able to compare grammars. As a world-renowned typologist and 
theorist, Bickel's supervision would have ensured that Schackow was very much up-to-date with not only general linguistics but also more recent topics in the typological literature (this is easier to identify through the ample bibliography in Schackow and through her choice of terminology than through the table of contents). Nonetheless a number of chapters and sections in Schackow's grammar can be tied directly back to influential work by Bickel: 'The geomorphic orientation system' (such as Bickel 1997, Bickel and Gaenszle ed. 1999), 'Nominalization and relativization' (Bickel 1999) but also lower-down sections in the table of contents, such as 6.4 'Reduplication, triplication and ideophones' (Rai et al 2005), to cite but a few examples.

\subsection{The influence of grammar and fieldwork manuals}

Grammar writing manuals range from relatively prescriptive guides to grammar writing (such as Aikhenvald 2015) to more general descriptions of data collection, analysis and grammarwriting (such as Evans et al 2006).

Some of these manuals contain advice about structuring a grammar and choosing what to include: Aikhenvald (2015) states that a chapter on word classes is essential in any grammar, even though this is far from the norm in our corpus. At the other end of the spectrum, we have Payne's (2014:95) suggestion that "classes such as 'Noun' and 'Verb' are no more than convenient approximations, rather than absolute categories," something with fits with the basic nominal vs verbal contrast characteristic of a subset of the grammars in our corpus.

Different motivations have driven some of the models or guides for grammar writing. Mithun 2007, for example, focuses on how to write grammars for communities of users. Other linguists make general suggestions about language descriptions (not necessarily grammars), such as Lehmann's 1999 suggestion that language descriptions should aim at three things (1) essential completeness; (2) intelligibility and (3) adequacy.

Some guides provide suggestions about the structuring of grammars. Aikhenvald (2015: 16), for example, proposes that introductory material about the language and its speakers be followed by a statement of phonology and phonetics, before sections on morphology, syntax, and possibly discourse properties and notes on lexical semantics. (Other types of organization are also possible, with syntax before morphology, so long as relevant facts about inflectional morphology are summarized first). Rice's 2007:147 recommendation is that "[t]he preferred order is phonetics/phonology - orthography - morphology - syntax semantics - pragmatics". In Mosel's 2006b structuring proposal, the grammar starts with an introductory phonology chapter and an overview of the structure of phrases, clauses and complex sentences. The grammar then proceeds in the traditional ascending linear fashion from word classes and morphology to simple clauses and complex sentences, in order to give the reader an idea of how the language works before they turn to chapters of particular interest.

These guides provide macro-level suggestions regarding the ordering of information in grammars, but others include much more detailed recommendations for chapter ordering and subsections: The appendix of Payne 2014 offers a possible outline for a balanced grammatical description. This details chapter, section and subsection headings, with items considered essential highlighted in each chapter: a section on Word Classes, and within that, sections on Nouns, Verbs and Pronouns with internal sections on Personal pronouns and Demonstrative pronouns. Payne notes that his proposal is just one possible outline for grammatical description and that it is not a checklist of what should be in a grammar but rather a source of ideas in developing a grammatical description. Unlike Payne, Bowern 2008 provides what she 
refers to as basic morphology/syntax checklist, based loosely on Comrie and Smith 1977. At the macro level it has sections on 'Verbs, Noun phrases, Case Marking, Adverbial phrases etc.', with nested sections and subsections: for example under Valency might be a section on Causatives with subsections on Causatives of intransitive verbs, transitive verbs, direct and indirect, omission of causer or causee. While there are correspondences across some of the sections suggested by Payne and Bowern, they differ in detail and in organizational structure, with Bowern placing a chapter or section on verbs prior to one on nouns.

Across this narrow survey of field manuals and grammar-writing guides it becomes clear that different scholars have different ideas regarding what a grammar might look like. Though van Driem 2002 suggests that the ordering of phonology and phonetics, morphophonology, morphology, morphosyntax "is conventional and friendly to the reader" (2002:121), the different structuring schemes we find across our corpus suggest that the notion of conventionality in grammar writing is less than clear. At a macro level at least, there are some similarities in the grammars in our corpus: they are all largely semasiological, conforming with what has been described for descriptive grammars the world over (Mosel 2006b, Lehmann and Maslova 2004). In the deeper levels of the hierarchy, some authors will have a more function-driven (or onomasiological) approach: In Turin 2012, within the chapter on Nominal morphology's section on Adverbs of time, a subsection is labeled 'Telling the time'. Apart from this, we do not find much evidence, in the layout of the grammars or their chapter, section and subsection headings, for what is recommended in Noonan 2007: using a form-oriented approach for the chapters on morphology and a function-oriented approach for chapters on syntax.

One indication of external influence is found in grammars that mention absent features in the language. Noonan (2007) reports considerable diversity of opinion in his survey of typologists and their assessment on whether the absence of a category should be explicitly highlighted in a grammar. He reports that Bickel, Comrie, Croft, and Haspelmath concur that it is good practice in an index to note "in boldface type the main entry [or entries] for a given feature, and noting the absence of a given feature directly in the index with the dash. So, for example, one could indicate the absence of tone as follows: tone: - ." (Noonan 2007: 116) For other linguists the possibilities in a language are too broad for this to be a feasible approach (Dahl 2016, Moravcsik 2016).

Language descriptions shaped by how they conform to an expected prototype are reminiscent of early missionary and other descriptive grammars using the Greco-Latin parts of speech grammatical model which maintain chapters for each part of speech, even if empty. For example, Hodgson 1857's Grammar of Vayu (which, though a language of Nepal, is not in our current corpus) contains a section on 'Ordinal numbers' which is simply followed by the text "There are none such" (1857: 392). Similarly, in a number of the grammars in our corpus, the descriptions refer to missing categories in comparison with neighboring languages: we find an echo of the missionary approach with Hari 2010 (herself a missionary) whose section 3.6.3 is entitled 'Conjunct/disjunct notion missing'. The text of the section states "Yohlmo does not follow the so-called conjunct/disjunct pattern" (2010: 55), and then gives the alternative means of expressing this.

As we've established here, the form and structure of a descriptive grammar is influenced by a range of factors and in turn may go on to further influence future grammars which then impact our theoretical understanding of these languages. While the languages in the corpus are classified taxonomically as Tibeto-Burman languages, they differ markedly in some key areas, as noted in the discussion of interjections and evidentiality. We also note 
differences in the table of contents reflecting differences in morphological complexity ${ }^{21}$ of verbal paradigms within language families. For example, morphologically complex Kiranti languages have the most verb-related sub-sections, e.g. Schakow's table of contents includes a section on The functions of the V2s which then has 26 sub-sections. So too with Van Driem's Dumi grammar which has a section on Morphology of the Simplicia with 26 sub-sections. These differences bring us back to the point made in Section 4.1 that the impact of what is immediately visible (and not visible) in a table of contents is important.

\section{Conclusion}

In this paper we have described a corpus of descriptive grammars and the database which we assembled in order to facilitate their comparison. Using this database, we were able to identify structural types that emerge from examining their organizational features, and looked in detail at how this plays out when looking at specific topics and their treatment in the grammars. In doing so, this paper illustrates how a grammar's structuring schemes are taken up across multiple generations of linguists in three centers of production of grammars of languages of Nepal. Beyond this, a close interrogation of the grammar database indicates a potential influence of field and grammar-writing manuals.

We see the relevance of this study as being focused on two primary areas:

a) for grammar-writers to become aware of the historical perspective that their grammars emerge from and fit into, and the potentially unconscious influences upon them; b) the pedagogical value of carrying out in-depth study of grammars--as opposed to reading them--from a particular region (whose comparability is thereby facilitated) and mapping out where similar content has been placed in the different descriptions. In essence, our database is an aligned corpus of grammars, opening up possibilities for terminological and organizational comparison in ways that have hitherto been more ad-hoc.

This study represents the first step of an ongoing program of large-scale analysis of grammars and how they are structured, which one might call 'empirical grammaticography', first extended to all published grammars of Nepal, then adding typologically different families and groups. It is important to note that while such an approach can allow for wide comparability, it will also bring to the fore the importance of how each of the parts fits into a broader system of categorization.

\section{Acknowledgments}

We wish to thank the following scholars for their comments and insights: Olivier Bonami, Lauren Gawne, Carol Genetti, John Mansfield, Didier Samain, Otto Zwartjes, as well as an anonymous reviewer. We are also grateful to a CNRS-University of Melbourne joint funding scheme which allowed us to initiate this collaborative research.

\section{References}

Aikhenvald, Alexandra Y. 2004. Evidentiality. Oxford: Oxford University Press. Aikhenvald, Alexandra Y. 2015. The art of grammar. Oxford: Oxford University Press.

\footnotetext{
${ }^{21}$ As discussed and defined in (Anderson 2015: 22)
} 
Aikhenvald, Alexandra Y. 2018. The Oxford handbook of evidentiality. Oxford Handbooks in Linguistics. Oxford: Oxford University Press.

Akita, Kimi \& Prashant Pardeshi (eds.). 2019. Ideophones, Mimetics and Expressives (Iconicity in Language and Literature 16). Amsterdam: Benjamins.

Ameka, Felix. 1992. Interjections: The universal yet neglected part of speech. Journal of Pragmatics 18. 101-118

Anderson, Stephen R. 2015. Dimensions of morphological complexity. In Matthew Baerman, Dunstan Brown \& Greville Corbett (eds.), Understanding and measuring morphological complexity, 11-26. Oxford: Oxford University Press.

Aussant, Emilie. 2017. La grammaire sanskrite étendue--Etat des Lieux. Histoire Epistémologie Langage 39 (2). 7-20.

Bickel, Balthasar. 1997. Spatial operations in deixis, cognition, and culture: where to orient oneself in Belhare. In Nuyts, Jan \& Eric Pederson (eds.), Language and Conceptualization, 46-83. Cambridge: Cambridge University Press.

Bickel, Balthasar. 1999. Nominalization and Focus in some Kiranti languages. In Yadava, Yogendra \& Warren Glover (eds.), Topics in Nepalese Linguistics, 271-96. Kathmandu: Royal Nepal Academy.

Bickel, Balthasar. 2003. Referential density in discourse and syntactic typology. Language, 79(4). 708-736.

Bradley, David. 1997. Tibeto-Burman languages and classification. In Bradley, David (ed.), Tibeto-Burman languages of the Himalayas, 1-72. Canberra: Pacific Linguistics

Bowern, Claire. 2008. Linguistic Fieldwork: A Practical Guide. Basingstoke, UK: Palgrave Macmillan.

Caplow, Nancy. 2017. Inference and deferred evidence in Tibetan. In Gawne, Lauren \& Nathan Hill (eds.), Evidential Systems of Tibetan Languages, 225-253. Berlin \& Boston: Mouton de Gruyter.

Caughley, Ross C. 2002. Ideophones in Chepang: Their nature and sub-categorisation. Gipan: Tribhuvan University Papers in Linguistics, 2 (May). 16-24.

Colombat, Bernard. In press. Accidens. In Colombat, Bernard \& Aimée Lahaussois (eds.) Histoire des parties du discours, 49-54. Orbis/Supplementa. Leuven: Peeters.

Colombat, Bernard. In press. Accidens. In Colombat, Bernard \& Aimée Lahaussois (eds.) Histoire des parties du discours, 54-56. Orbis/Supplementa. Leuven: Peeters.

Colombat, Bernard \& Aimée Lahaussois (eds.). In press. Histoire des parties du discours. Orbis/Supplementa. Leuven: Peeters.

Colombat, Bernard \& Aimée Lahaussois. Les parties du discours ou classes de mots. In press. In Colombat, Bernard \& Aimée Lahaussois, Aimée, (eds.). Histoire des parties du discours, 24-45. Orbis/Supplementa. Leuven: Peeters.

Colombat, Bernard, Jean-Marie Fournier \& Christian Puech. 2010. Histoire des idées sur le langage et les langues. Paris: Klincksiek.

Comrie, Bernard \& Norval Smith. 1977. Lingua Descriptive Studies: Questionnaire. Lingua 42(1). 11-71.

Dahl, Östen. 2016. Thoughts on language: Specific and crosslinguistic entities. Linguistic Typology (2). 426-436.

DeLancey, Scott. 2002. Relativization and Nominalization in Bodic, Proceedings of the TwentyEighth Annual Meeting of the Berkeley Linguistics Society: Special Session on TibetoBurman and Southeast Asian Linguistics. 55-72.

DeLancey, Scott. 2012. Still mirative after all these years. Linguistic Typology 16 (3). 529-564. 
Dingemanse, Mark. 2011. The Meaning and use of ideophones in Siwu. Nijmegen: Radboud University PhD thesis.

Dingemanse, Mark. 2018. Redrawing the Margins of Language: Lessons from research on ideophones. Glossa 3(1), 4.

Dixon, Robert M. W. 2010. Basic Linguistic Theory. Oxford: Oxford University Press.

Doornenbal, Marius. 2009. A Grammar of Bantawa: Grammar, paradigm tables, glossary and texts of a Rai language of Eastern Nepal. Utrecht: LOT.

van Driem, George. 1987. A grammar of Limbu. Mouton Grammar Library 4. Berlin \& New York: Mouton de Gruyter.

van Driem, George. 1993. A grammar of Dumi. Mouton Grammar Library 10. Berlin \& New York: Mouton de Gruyter.

van Driem, George. 2007. A holistic approach to the fine art of grammar writing: The Dallas Manifesto, In Novel Kishore Rai, Yogendra Prasad Yadav, Bhim N. Regmi \& Balaram Prasain (eds.), Recent Studies in Nepalese Linguistics, 93-184. Kathmandu: Linguistic Society of Nepal.

Dryer, Matthew. 2006. Descriptive theories, explanatory theories, and basic linguistic theory. In Ameka Felix, Alan Dench \& Nicholas Evans (eds.), Catching language: Issues in grammar writing, 207-234. Berlin: Mouton de Gruyter.

Dryer, Matthew \& Martin Haspelmath (eds.). 2013. The World Atlas of Language Structures Online. Leipzig: Max Planck Institute for Evolutionary Anthropology (available online at http://wals.info).

Ebert, Karen. 1997a. Camling (Chamling). Languages of the World/Materials 103. Munich: Lincom Europa.

Ebert, Karen. 1997b. A grammar of Athpare. Munich: Lincom Europa.

Ebert, Karen. 2000. Camling texts and glossary. Languages of the World/Text collections 11. Munich: Lincom Europa.

Evans, Nicholas \& Alan Dench. 2006. Introduction: Catching Language. In Ameka, Felix, Alan Dench \& Nicholas Evans (eds.), Catching Language: The Standing Challenge of Grammar Writing, 1-40. Berlin \& New York: Mouton De Gruyter.

François, Jacques. 2013. Deux pionniers de la formalisation en morphologie linguistique au XIXe siècle : August Schleicher et Hugo Schuchardt. Histoire Epistémologie Langage 35 (1). 111-142.

Garrett, Edward J. 2001. Evidentiality and Assertion in Tibetan. Los Angeles: University of California PhD thesis.

Gawne, Lauren. 2013 Lamjung Yolmo copulas in use: evidentiality, reported speech and questions. Melbourne: University of Melbourne PhD thesis.

Gawne, Lauren. 2016. A sketch grammar of Lamjung Yolmo. Canberra: Pacific Linguistics Gawne, Lauren, Barbara Kelly, Andrea Berez-Kroeker \& Tyler Heston. Putting practice into words: The state of data and methods transparency in grammatical descriptions. Language Documentation \& Conservation 11. 157-189

Gawne, Lauren \& Nathan Hill (eds.). 2017. Evidential Systems of Tibetan Languages. Berlin \& Boston: Mouton de Gruyter.

Genetti, Carol. 1990. A descriptive and historical account of the Dolakha Newari dialect. Eugene: University of Oregon PhD dissertation.

Genetti, Carol. 1994. A Descriptive and historical account of the Dolakha Newari dialect. Tokyo: Institute for the study of languages and cultures of Asia and Africa. 
Genetti, Carol. 2007. A Grammar of Dolakha Newar. Mouton Grammar Library 40. Berlin \& New York: Mouton de Gruyter.

Genetti, Carol. 2011. Basic Linguistic Theory Review. Language 87(4). 899-904

Genetti, Carol. 2014. Walking the line: Balancing description, argumentation and theory in academic grammar writing. In Nakayama, Toshihide \& Keren Rice (eds.), The Art and Practice of Grammar Writing (Language Documentation and Conservation Special Publication No. 8), 121-134. Honolulu: University of Hawai'i Press.

Genetti, Carol, Alexander Coupe, Ellen Bartee, Kristine Hildebrandt \& You-Jing Lin. 2008. Syntactic Aspects of Nominalization in Five Tibeto-Burman Languages of The Himalayan Area, Linguistics of the Tibeto-Burman Area. Volume 31(2). 97-143.

Grimes, Barbara (ed.), Joseph Grimes \& Richard Pittman (consulting eds.). 1988. Ethnologue: Languages of the world. Dallas, Texas: Summer Institute of Linguistics. 11th edition.

Haiman, John. 2018. Ideophones and the evolution of language. Cambridge: Cambridge University Press.

Hale, Austin. 1980. Person markers: Finite conjunct and disjunct verb forms in Newari. Papers in South-East Asian linguistics 7. 95-106.

Hammarström, Harald \& Robert Forkel \& Martin Haspelmath. 2019.

Glottolog 3.4. Jena: Max Planck Institute for the Science of Human History.

(Available online at http://glottolog.org, Accessed on 2019-05-13.)

Hargreaves, David. 2018. “Am I blue?": Privileged access constraints in Kathmandu Newar. In Floyd, Simeon, Elisabeth Norcliffe \& Lila San Roque (eds.). Egophoricity, 79-107.

Amsterdam: John Benjamins.

Hari, Anna Maria. 2010. Yohlmo Grammar Sketch. SIL International.

Hildebrandt, Kristine. 2004. A grammar and glossary of the Manange language. In Genetti, Carol (ed.). Tibeto-Burman languages of Nepal: Manange and Sherpa, 7-192. Canberra: Pacific Linguistics.

Hill, Nathan W. 2012. 'Mirativity' does not exist: hdug in 'Lhasa' Tibetan and other suspects. Linguistic Typology 16 (3). 389-433

Hinton, Leanne, Johanna Nichols \& John Ohala (eds.). 1994. Sound symbolism. Cambridge: Cambridge University Press.

Hodgson, BH. 1857. Vayu Vocabulary. Journal of The Asiatic Society of Bengal 26. 372-485.

Kelly, Barbara. 2018. Interaction of speaker knowledge and volitionality in Sherpa. In Floyd, Simeon, Elisabeth Norcliffe \& Lila San Roque (eds.), Egophoricity, 139-152.

Amsterdam: John Benjamins.

Kelly, Barbara. 2004. A grammar and glossary of the Sherpa language. In Genetti, Carol (ed.), Tibeto-Burman languages of Nepal: Manange and Sherpa, 193-321. Canberra: Pacific Linguistics.

King, John. 2009. A grammar of Dhimal. Leiden: Brill.

Lahaussois, Aimée. In press. The shapes of verbal paradigms in Kiranti languages. Faits de Langues.

Lahaussois, Aimée. 2019. Les parties du discours dans les manuels de description linguistique." In Fournier, Jean-Marie, Lahaussois, Aimée \& Valérie Raby (eds.), Grammaticalia : Hommage à Bernard Colombat. Lyon: ENS Editions.

Lahaussois, Aimée. 2017. Ideophones in Khaling. Linguistics of the Tibeto-Burman Area 40.2. 179-201.

Lahaussois, Aimée. 2016. Where have all the interjections gone? A look into the place of interjections in contemporary grammars of endangered languages. In Assunção, Carlos, 
Gonçalo Fernandes \& Rolf Kemmler (eds.), Tradition and Innovation in the History of Linguistics: Contributions from the 13th International Conference on the History of the Language Sciences (ICHoLS XIII), Vila Real, 25-29 August 2014. Münster: Nodus Publikationen.

Lallot, Jean. In press. Parapomenon. In Colombat, Bernard \& Aimée Lahaussois (eds.) In press. Histoire des parties du discours, 45-48. Orbis/Supplementa. Leuven: Peeters. Lambert-Brétière, Renée. In press. The Bloomfieldian Heritage in Algonquian linguistics: The verbal complex in Innu. Faits de Langues.

Lazard, Gilbert. 1999. Mirativity, evidentiality, mediativity, or other? Linguistic Typology 3. 91109

Lehmann, Christian \& Elena Maslova. 2004. Grammaticography. In Geert Booij, Christian Lehmann, Joachim Mugdan \& Stavros Skopeteas (eds.), Morphologie. Ein Handbuch zur Flexion und Wortbildung, Vol. 2, Berlin \& New York: De Gruyter.

Matisoff, James. 1972. Lahu nominalization, relativization and genitivization. In Kimball, John (ed.), Syntax and Semantics, 237-57. New York: Seminar Press.

Michailovsky, Boyd. 1988, La langue hayu. Paris: Editions du CNRS.

Mithun, Marianne. 2007. Grammars and Community. In Payne, Thomas \& David Weber (eds.), Perspectives on Grammar Writing (Benjamins Current Topics Vol 11), 45-70. Amsterdam/Philadelphia: John Benjamins.

Mosel, Ulrike. 2006a. Sketch Grammar. In Gippert, Jost, Nikolaus Himmelmann \& Ulrike Mosel (eds.), Essentials of language documentation, 301-310. Berlin \& New York: Mouton De Gruyter.

Mosel, Ulrike. 2006b. Grammaticography: The art and craft of writing grammars. In Ameka, Felix, Alan Dench \& Nicholas Evans (eds.), Catching Language: The standing challenge of grammar writing, 41-68. Berlin \& New York: Mouton De Gruyter.

Moravcsik, Eve. 2016. On linguistic categories. Linguistic Typology 20(2). 417-426.

Moseley, Christopher (ed.). 2010. Atlas of the World's Languages in Danger, 3rd edition. Paris: UNESCO Publishing.

Mushin, Ilana. 2013. Making knowledge visible in discourse: Implications for the study of linguistic evidentiality. Discourse Studies (Special Issue on Epistemic Discourse Analysis) 15(5). 627-645

Nida, Eugene. 1949. Morphology: the descriptive analysis of words. Ann Arbor, MI: University of Michigan Press.

Noonan, Michael. 1997. Versatile nominalizations. In Joan Bybee, John Haiman, \& Sandra A. Thompson (eds.), Essays on language function and language type, 373-94. Amsterdam: Benjamins.

Noonan, M. 2007. Grammar Writing for a grammar-reading audience. In Payne, Thomas \& David Weber (eds.). Perspectives on grammar writing (Benjamins Current Topics Vol 11), 113-126. . Amsterdam/Philadelphia: John Benjamins.

Dryer, Matthew S. \& Martin Haspelmath (eds.). 2013. The World Atlas of Language Structures Online. Leipzig: Max Planck Institute for Evolutionary Anthropology. (Available Online http://Wals.Info, Accessed on 2018-02-16.)

Pawley, Andrew. 2014. Grammar Writing from a dissertation advisor's perspective. In Nakayama, Toshihide \& Keren Rice (eds.), The Art and Practice of Grammar Writing (Language Documentation and Conservation Special Publication No. 8), 7-24. Honolulu: University of Hawai'i Press. 
Payne, Thomas. 2007. A grammar as a communicative act, or What does a grammatical description really describe? In Payne, Thomas \& David Weber (eds.), Perspectives on Grammar Writing (Benjamins Current Topics Vol 11), 127-142. Amsterdam/Philadelphia: John Benjamins.

Poudel, Kedar Prasad. 2006. Dhankute Tamang Grammar. Munich: Lincom Europa.

Rai, Novel Kishore, Balthasar Bickel, Martin Gaenszle, Elena Lieven, Netra P. Paudyal, Ichchha Purna Rai, Manoj Rai \& Sabine Stoll. 2005. Triplication and ideophones in Chintang. In Yadava, Yogendra P. (ed.), Current Issues In Nepalese Linguistics, 205-209. Kirtipur: Linguistic Society of Nepal.

Rai, Novel Kishore \& Werner Winter. 1997. Triplicated verbal adjuncts in Bantawa. In David Bradley (ed.), Tibeto-Burman Languages of the Himalayas, 119-134. Canberra: Pacific Linguistics.

Regmi, Dan Raj, 2012. A Grammar of Bhujel. Munich: Lincom Europa.

Rice, Keren. 2007. A typology of good grammars. In Payne, Thomas \& David Weber (eds.), Perspectives on grammar writing (Benjamins Current Topics 11), 143-172.

Rutgers, Roland. 1998. Yamphu: Grammar, text \& lexicon. Leiden: Research School CNWS.

Samarin, William J. 1967. Field Linguistics. A guide to linguistic field work. New York: Holt, Rinehart \& Winston.

Schackow, Diana. 2015. A grammar of Yakkha (Studies in Diversity Linguistics 7). Berlin: Language Science Press.

Schleicher, August. 1861. Compendium der vergleichenden Grammatik der indogermanischen Sprachen. Weimar: H. Böhlau.

Smith-Stark, Thomas. 2009. La trilogía catequística: Artes, Vocabularios y Doctrinas en la Nueva España como instrumento de una política lingüística de normalización. In Barriga Villanueva, Rebeca \& Pedro Martín Butragueño (eds.), Historia Sociolingüística de México. Vol. I: México prehispánico y colonial, 451-482. México D.F.: El Colegio de México

Voeltz, Erhard \& Christa Kilian-Hatz (eds.). 2001. Ideophones. Amsterdam \& Philadelphia: Benjamins.

Tournadre, Nicolas. 1992. La déixis en tibétain: quelques faits remarquables. In Morel M.-A. \& L. Danon-Boileau (eds.), La Deixis, 197-208. Paris: Presses Universitaires de France.

Tournadre, Nicolas. 1994. Personne et médiatifs en tibétain. Faits de langues 3. 149-158

Turin, Mark. 2012. A grammar of the Thangmi Language: With an ethnographic introduction to the speakers and their culture. Leiden: Brill.

Watters, David. 2002. A grammar of Kham. Cambridge: Cambridge University Press.

Woodbury, Anthony. 1986. Interactions of tense and evidentiality: A study of Sherpa and English. In Chafe, Wallace \& Johanna Nichols (eds.), Evidentiality: The Linguistic Coding of Epistemology, 188-202. Norwood: Ablex Publishing Corporation. 